\title{
Epidemiology and pathology of Anguillicoloides crassus in European eel Anguilla anguilla from the Tagus estuary (Portugal)
}

\author{
Ana Filipa Neto ${ }^{1}$, José Lino Costa ${ }^{1}$, Maria José Costa ${ }^{1,2}$, Isabel Domingos ${ }^{1,2, *}$ \\ ${ }^{1}$ Centro de Oceanografia and ${ }^{2}$ Departamento de Biologia Animal, Faculdade de Ciências da Universidade de Lisboa, \\ Campo Grande, 1749-016 Lisboa, Portugal
}

\begin{abstract}
Infection of the European eel Anguilla anguilla by the swimbladder nematode Anguillicoloides crassus was investigated for the first time at 5 sampling sites in the Tagus estuary (Portugal). A total of 332 yellow eels were examined, revealing a prevalence of $56 \%$ and a mean intensity of 3.2 lumen worms per swimbladder. The effect of the host's sex and size on parasitism descriptors was studied. Only total length (TL) was considered a significant determinant, with larger eels harbouring a higher number of nematodes. Eels were parasitized in 4 of the 5 sampling sites, with prevalence values following the salinity gradient along the Tagus estuary. No signs of the nematode were observed in the most saline site. Variations in the intensity of infection were only apparent when a large geographic scale including a wide temperature range was considered. Although $68 \%$ of the analysed eels showed pathological damage to the swimbladder caused by the parasite, injuries were relatively reduced in comparison with other studies. No effect of the infection on the condition of the body and on liver condition was detected. However, considerable spleen enlargement was observed with increasing parasite load, which could be related to the bloodsucking activity of this nematode.
\end{abstract}

KEY WORDS: European eel · Swimbladder nematode $\cdot$ Sexual, ontogenic, and spatial variation · Infection $\cdot$ Host condition $\cdot$ Portugal

\section{INTRODUCTION}

The swimbladder nematode Anguillicoloides crassus Kuwahara, Niimi \& Hagaki 1974, recently transferred from the genus Anguillicola by Moravec (2006), is a natural parasite of the Japanese eel Anguilla japonica (Temminck \& Schlegel 1847). After its introduction into Europe, probably through the uncontrolled intercontinental import of infected eels from Eastern Asia, it rapidly spread among the European eel Anguilla anguilla (L., 1758) (Kennedy \& Fitch 1990, Køie 1991). The life-cycle of this nematode (Haenen et al. 1989, De Charleroy et al. 1990, Haenen \& Van Banning 1990) as well as its colonisation, epidemiology, and dissemination in specific countries or regions (e.g. Kennedy \& Fitch 1990, Thomas \& Ollevier 1992, Würtz et al. 1998, Morrissey \&
McCarthy 2007), have been investigated by a number of studies. In addition, some authors have discussed the impact that environmental variables such as temperature and salinity could have on infection levels (e.g. Knopf et al. 1998, Kirk et al. 2000a,b, 2002), while others have focused on the condition of eels and on swimbladder dysfunction (e.g. Höglund et al. 1992, Würtz \& Taraschewski 2000, Sures et al. 2001). It has been hypothesized that these adverse effects might result either from the parasite's bloodsucking activity and the subsequent energy cost, or from mechanical injuries caused to the swimbladder wall (Höglund et al. 1992), which together could prevent eels from reaching their spawning ground (Kirk 2003). In fact, a recent study has shown that infection and damage of this hydrostatic organ could impair host swimming performance and increase overall 
energy consumption, representing a serious threat for the reproductive success of European eels (Palstra et al. 2007).

Although Anguillicoloides crassus parasitism has already been reported in many European countries, very little is known in Portugal with respect to this infection and its consequences on the definitive host population. This evaluation is especially important because $A$. anguilla is a valuable, high-economic resource (Domingos 2003) that is in drastic decline throughout its distribution area (Feunteun 2002). Hence, the present study objectives were to (1) estimate the extent of A. crassus infection in eels from the Tagus estuary, the largest national brackish water system; (2) investigate the effect of host sex and size on the prevalence and intensity of infection; (3) evaluate the nematode's spatial variation according to the distribution of its definitive host in estuarine environments; (4) assess the mechanical damage to the swimbladder as a result of parasite pressure and to identify the variables that might affect it; and (5) examine the potential consequences of this nematode on the eels' general health.

\section{MATERIALS AND METHODS}

Study area. The Tagus estuary $\left(38^{\circ} 44^{\prime} \mathrm{N}, 9^{\circ} 08^{\prime} \mathrm{W}\right)$, covering an area of $320 \mathrm{~km}^{2}$, is one of the largest estuaries in the European Atlantic coast and the Iberian Peninsula's most important one (Costa 1999). Sampling sites (Fig. 1) were established according to their distance to the sea and physicochemical characteristics, specifically considering the salinity gradient (Costa 1999) and taking into account areas where Anguilla anguilla specimens are known to be present in significant numbers (Costa et al. 2008). Carregado (C) and Vila Franca de Xira (VF) are located in the upper estuary. Nevertheless, $\mathrm{C}$ is situated in the tidal estuary (salinity 0) whereas VF is already part of the saline estuary (salinity 0-10). In the middle estuary, namely in Alcochete (A) and in Vasco da Gama bridge (VG) sites, salinity values are higher (salinity 10-15 and 20-25, respectively). Barreiro (B) is the most downstream site and has the highest salinity values (salinity 30-35), sometimes with values comparable to the marine environment.

Field sampling and laboratory work. Sampling in each site was performed in May and June 2007. Eels were obtained from local fishermen, who caught them using fyke nets and longlines. Immediately after capture, the eels were transported to the laboratory, killed by an overdose of benzocaine, and frozen for further analysis. The total weight of each fish was recorded to the nearest $\mathrm{g}$, and its total length (TL) was measured to the nearest $\mathrm{mm}$. Following dissection, individuals were examined

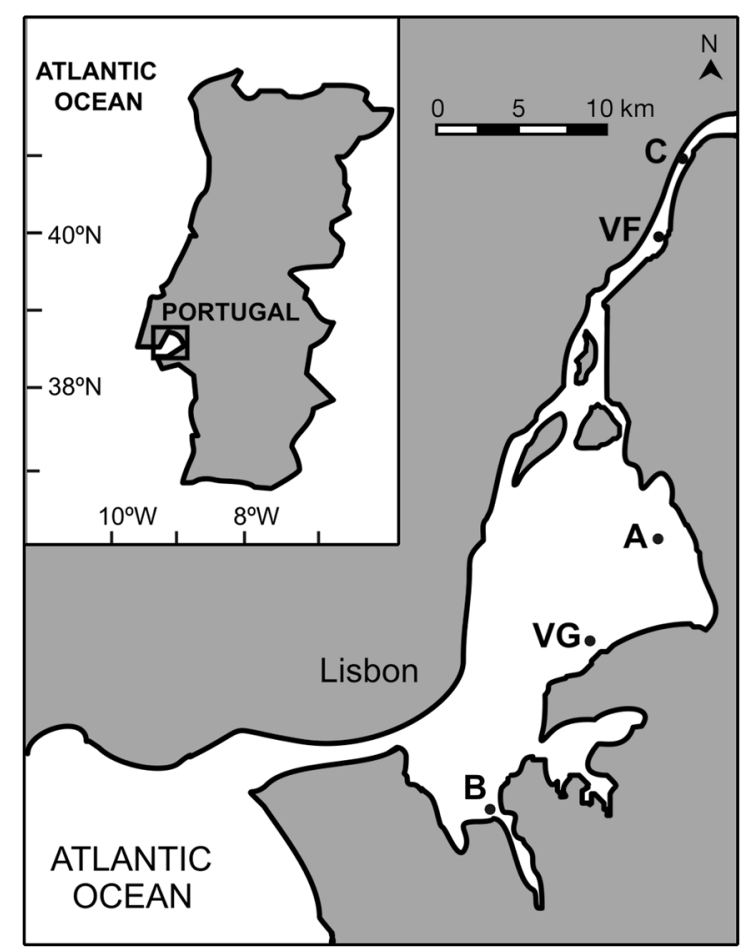

Fig. 1. Study area and location of sampling sites (•). C: Carregado; VF: Vila Franca de Xira; A: Alcochete; VG: Vasco da Gama bridge; B: Barreiro

under a binocular microscope for sex determination using the methodology described by Domingos (2003). Afterwards, their viscera were removed and eviscerated specimens were weighed to the nearest $g$. The weight of 2 important organs (liver and spleen) was also determined to the nearest $0.1 \mathrm{~g}$. The swimbladder of all eels was examined macroscopically, and the number of adults and sub-adults of Anguillicoloides crassus recorded. Additionally, the health status of this hydrostatic organ was assessed using the swimbladder degenerative index (SDI) to measure the mechanical damage resulting from parasite pressure (Lefebvre et al. 2002a). This evaluation is based on 3 criteria (transparency/opacity, pigmentation/exudates, and thickness), with each one being coded by the scores 0,1 , or 2 (increasing degradation). Thus, the cumulative index (i.e. SDI classes) can range from 0 (no pathological signs of infection) to 6 (extremely damaged swimbladder).

Data analysis. Anguillicoloides crassus infection was described using parasite prevalence (\% infected hosts), mean parasite abundance (nematode count over the whole group of eels), and mean parasite intensity (nematodes per infected host) according to Bush et al. (1997). The variance-to-mean ratio $\mathrm{s}^{2} / \bar{x}$ of the parasite abundance was also calculated to assess the degree of dispersion of the parasite in the host population (Audenaert et al. 2003). 
As prevalence and intensity are the most frequently used descriptors in parasitic studies (Rózsa et al. 2000), only these were considered for further statistical analyses, namely comparison according to sex, size classes, and sampling sites. Prevalence values were compared using the $G$-test of independence with Williams's correction $\left(G_{\mathrm{W}}\right.$ i Sokal \& Rohlf 1995) and differences in median intensities tested using the Kruskal-Wallis test ( $H$; Siegel \& Castellan 1988).

Parasitic descriptors were compared according to the biological variables (sex and size of the host) exclusively in one sampling site to eliminate the effect that spatial heterogeneity might have on Anguillicoloides crassus epidemiology. Due to the small sample size for representation of all size/sex classes in most sites and the associated lack of statistical power, the site selected for statistical analysis was C. For comparison among sexes, both sexually differentiated eels (males and females) and undifferentiated individuals were considered. Moreover, a specific size class $(240 \mathrm{~mm} \leq$ $\mathrm{TL}<350 \mathrm{~mm}$ ) was selected, so that variation according to length would be negligible. To investigate trends according to eel size, 2 classes were defined (TL < $300 \mathrm{~mm}$ and TL $\geq 300 \mathrm{~mm}$ ) based on the dietary changes that occur as eels grow, specifically modifications in their preferential prey (Costa et al. 1992), which might affect $A$. crassus infection (Kirk 2003). In addition, Spearman's rank correlation test $\left(\mathrm{r}_{\mathrm{S}}\right.$ Siegel \& Castellan 1988) was used to measure the relationship between host size and intensity of infection. To examine whether prevalence and intensity of the parasite differed among sampling sites (C, VF, A, VG, and B) only larger females ( $\mathrm{TL} \geq 300 \mathrm{~mm}$ ) were used in order to eliminate any effect due to the eel's biological characteristics.

To evaluate the factors that may affect Anguillicoloides crassus prevalence and intensity at a large spatial scale a multiple linear regression (Sokal \& Rohlf 1995) was performed, using larger eels from all of the present sampling sites and from other geographic brackish areas from recent studies. The predictor variables used in this analysis were system type (estuary or coastal lagoon), latitude (which reflects temperature), and salinity.

Some variables including sex, TL, eviscerated weight, parasite presence/absence, Anguilla crassus abundance and intensity were also simultaneously explored using a multiple linear regression procedure to assess their effects on SDI. Additionally, variation among SDI classes was further investigated for those variables that were included in the model. Comparisons between groups were performed using the Kruskal-Wallis test. These analyses were done exclusively in one sampling site to eliminate the effect that spatial heterogeneity might have on swimbladder damage. The selected site (A) was chosen because it was the only site that ensured an adequate sample of eels to analyse all of the biological parameters considered in the multiple regression procedure.

The standard condition indices, usually calculated to test the effect of this parasite infection on eels, were replaced by the study of the biometric variables themselves. This method avoids the application of biased indices when there is an allometric variation in growth (Jakob et al. 1996), as happens in Anguilla anguilla (Tesch 1977). Considering the various measures of parasite pressure, differences in eels' eviscerated weight were investigated using analysis of covariance (ANCOVA) (Sokal \& Rohlf 1995). The same procedure was done in relation to liver and spleen weight with TL (in the first case) and eviscerated weight (for both organs) used as covariates. Measures of parasite pressure were considered as categorical factors and included the parasite abundance index (Ab), which was coded using 3 load classes $\left(\mathrm{Ab}_{0}\right.$ : 0 parasites, $A b_{1}: 1$ to 3 parasites, $A b_{2}$ : $\geq 4$ parasites), and the SDI classes. These analyses were done exclusively in one sampling site to eliminate the effect that spatial heterogeneity might have on the eel's condition. The selected site (A) was chosen for the same reasons described in the previous analysis.

The $G_{\mathrm{W}}$ and ANCOVA tests were conducted using BIOMstat 3.0 software, whereas the other tests were performed using the STATISTICA 8.0 package (StatSoft). The level of significance used in all analyses was $<0.05$.

\section{RESULTS}

\section{Anguillicoloides crassus infection}

A total of 332 yellow eels, with TL ranging from 158 to $700 \mathrm{~mm}$ (mean $=346 \pm 123 \mathrm{~mm}$ ) and eviscerated weight ranging from 5 to $574 \mathrm{~g}$ (mean = $96 \pm 114 \mathrm{~g}$ ), were analysed. Considering all examined eels, Anguillicoloides crassus infection reached a prevalence of $56 \%$. Although the maximum number of nematodes observed per swimbladder was 22, the majority of infected eels harboured 1 or 2 parasites $(71 \%)$ and to a lesser extent 3 to 5 nematodes $(27 \%)$. The mean abundance of parasitism was $1.8 \pm 2.7$, and the mean intensity of infection was $3.2 \pm 2.9$. The variance-tomean ratio of parasite abundance was $>1\left(\mathrm{~s}^{2} / \bar{X}=2.4\right)$, indicating an aggregated distribution.

\section{Effect of host sex and size}

No significant differences were found among eel sexes either for prevalence or median intensity of infection (Fig. 2a). Although prevalence did not vary 
significantly between size classes, the number of parasites per infected eel was significantly higher in larger specimens (Fig. 2b), with a significant positive correlation between intensity of infection and the eel's TL $\left(\mathrm{r}_{\mathrm{S}}=\right.$ $0.42, \mathrm{n}=36, \mathrm{p}<0.05)$.

\section{Spatial variation}

Prevalence was significantly different among sampling sites, namely because none of the 33 eels captured at B were infected (Fig. 3). In relation to intensity of infection, no significant differences were found among sites (Fig. 3). Nevertheless, it should be noted that B was not included in the latter statistical analysis because intensity only includes infected individuals.

Table 1 presents the data used to determine the environmental variables that influence both parasitism
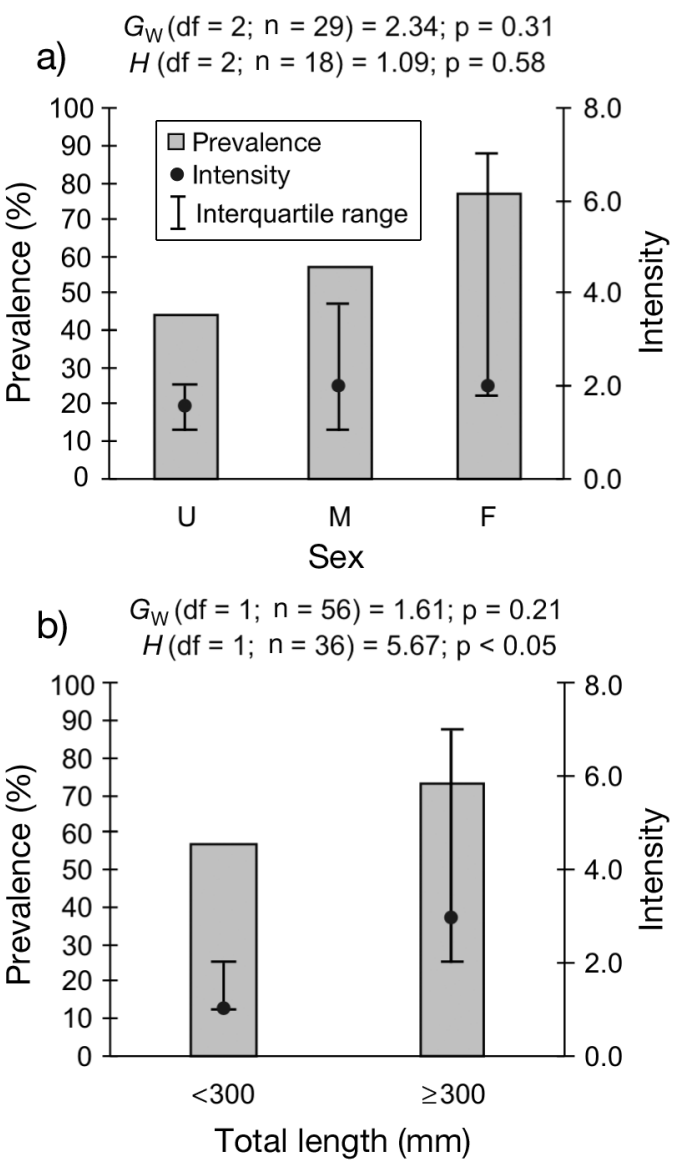

Fig. 2. Anguilla anguilla infected by Anguillicoloides crassus. Prevalence and median intensity of the parasite in eels from the Tagus estuary according to (a) sex and (b) ontogeny. $G_{\mathrm{W}}$ : result of the $G$-test of independence with Williams's correction for testing prevalence variation; $H$ : result of the Kruskal-Wallis test for testing intensity variation; $\mathrm{U}$ : undifferentiated; $\mathrm{M}$ : male; F: female descriptors. While no significant model was obtained for prevalence, mean intensity of infection was explained by a set of the tested variables $\left(\mathrm{r}^{2}=0.31, F=\right.$ 5.873, df $=2,19, \mathrm{n}=22, \mathrm{p}<0.05)$. Latitude showed the strongest influence on Anguillicoloides crassus intensity $(t=-3.109, \mathrm{p}<0.01)$ followed by system type $(t=$ $-2.790, \mathrm{p}<0.05$ ), with more nematodes observed in southern latitudes and in coastal lagoons. In contrast, salinity did not present a significant effect in the model $(\mathrm{p}>0.05)$.

\section{Swimbladder mechanical damage}

The proportion of eels per SDI class revealed that $32 \%$ of the swimbladders examined were classified as intact, $60 \%$ moderately damaged, and 8\% severely damaged (Fig. 4a). The mean SDI value obtained was $1.37 \pm 1.30$. Regarding the 3 criteria used in the SDI, a thickened swimbladder wall was rarely observed, contrary to transparency/opacity and pigmentation/ exudates, which were detected in more than half of the studied eels (Fig. 4b).

A model including Anguillicoloides crassus abundance and eel TL significantly explained the observed swimbladder mechanical damage $\left(\mathrm{r}^{2}=0.25, F=11.192\right.$, $\mathrm{df}=2,60, \mathrm{n}=63, \mathrm{p}<0.001)$. Parasite abundance had the strongest influence on the SDI $(t=3.996, \mathrm{p}<0.001)$ followed by host size $(t=2.606, \mathrm{p}<0.05)$. Variation in both explanatory variables per SDI classes is illustrated in Fig. 5. Median abundance was significantly different among SDI classes $(H=22.055, \mathrm{df}=5, \mathrm{n}=63, \mathrm{p}<0.001)$, showing a considerable increase as values of SDI became higher, except for severely damaged swimblad-

$$
\begin{gathered}
G_{W}(d f=4 ; n=172)=49.72 ; p<0.001 \\
H(d f=3 ; n=79)=1.51 ; p=0.68
\end{gathered}
$$

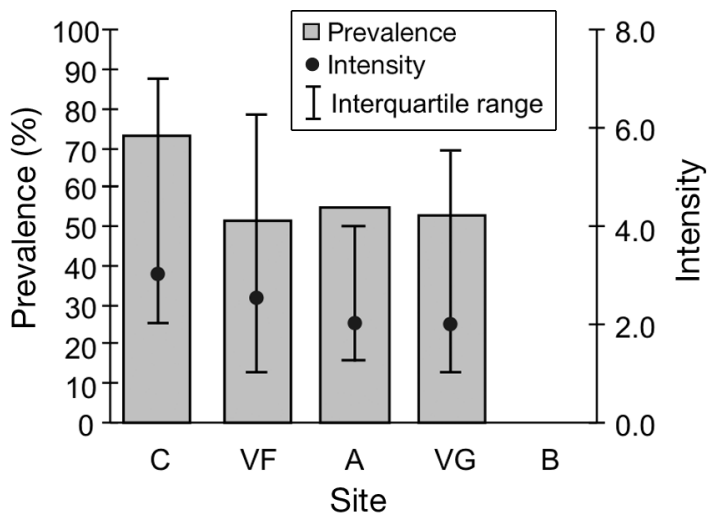

Fig. 3. Anguilla anguilla infected by Anguillicoloides crassus. Prevalence and median intensity of the parasite in eels from the Tagus estuary according to spatial variation. See Figs. 1 \& 2 for abbreviations 
ders, which harboured fewer parasites than moderately affected ones (Fig. 5a). In relation to TL, no significant differences were obtained among the various SDI classes $(H=6.658, \mathrm{df}=5, \mathrm{n}=63, \mathrm{p}=0.247)$. Nevertheless, a general trend of increasing swimbladder injuries with host size was observed (Fig. 5b).

\section{General health condition of eels}

Controlling for the respective covariates, neither eviscerated weight nor liver weight varied significantly according to the measures of parasite pressure tested (Table 2). On the contrary, spleen weight was affected by Anguillicolloides crassus abundance (Table 2), showing a significant enlargement in eels with 4 or more nematodes $\left(\mathrm{Ab}_{2}\right)$.

\section{DISCUSSION}

\section{Anguillicolloides crassus infection}

The present study is the first documented report on the invasion of Anguillicolloides crassus in the Tagus estuary. Factors that led to the nematode introduction in this system are unknown, but it might be assumed that, like in other European systems (revision in Kirk 2003), uncontrolled trade of eels was a major factor. The dynamics of this infection are characterized by a rapid increase in prevalence and intensity values that tend to stabilize at a particular value (e.g. Audenaert et al. 2003, Lefebvre \& Crivelli 2004, Schabuss et al. 2005). The lack of previous data prevents the understanding if parasitism in the Tagus estuary is presently established or still in expansion. Although direct comparison with data in the literature is difficult due to differences in sample or host size (Lefebvre et al. 2002b), Table 1 shows that the epidemiological levels observed are similar to those reported in other areas where the nematode population is considered steady. However, it must be mentioned that larval stages (L3 and L4) were not considered in the present study, which implies that the real $A$. crassus infection could be underestimated.

\section{Effect of host sex and size}

No effect of host sex was observed on parasitism descriptors, similar to the results obtained by Schabuss et al. (2005). Although Morrissey \& McCarthy (2007) verified higher intensities in male than in female hosts, they suggested that those differences were related to Anguilla anguilla trophic ecology, interhabitat move-

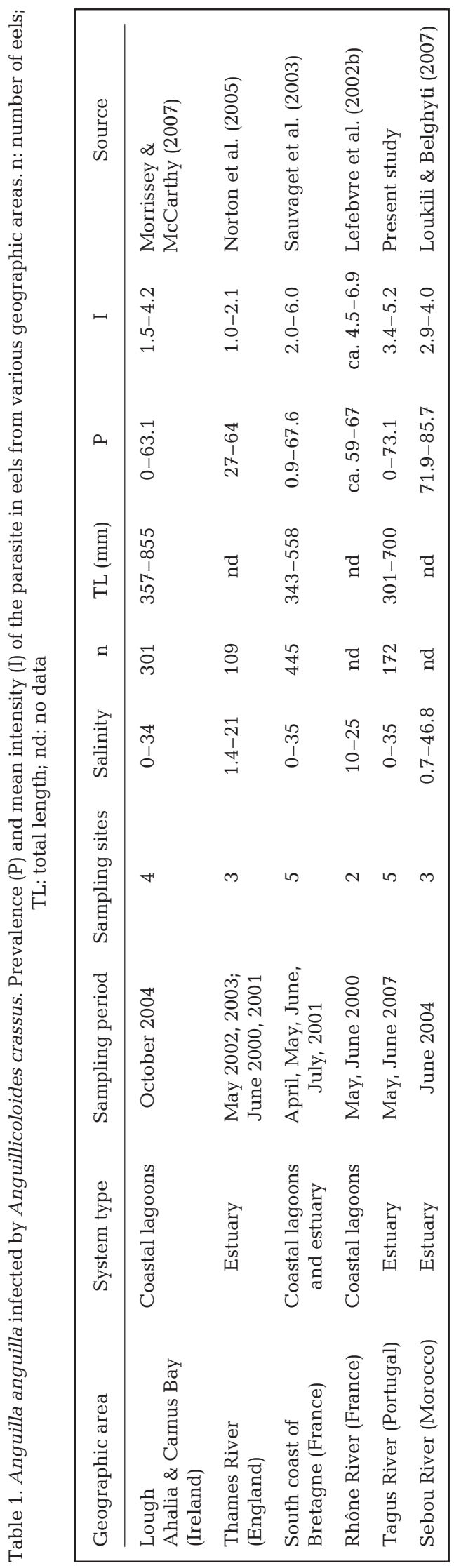


b)

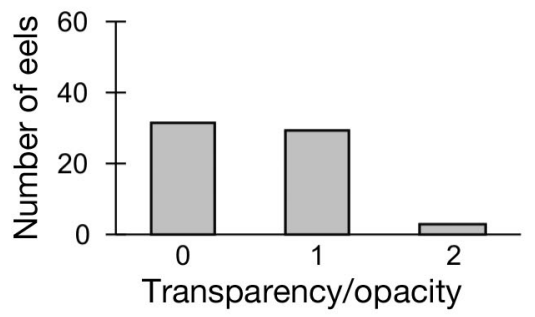

a)

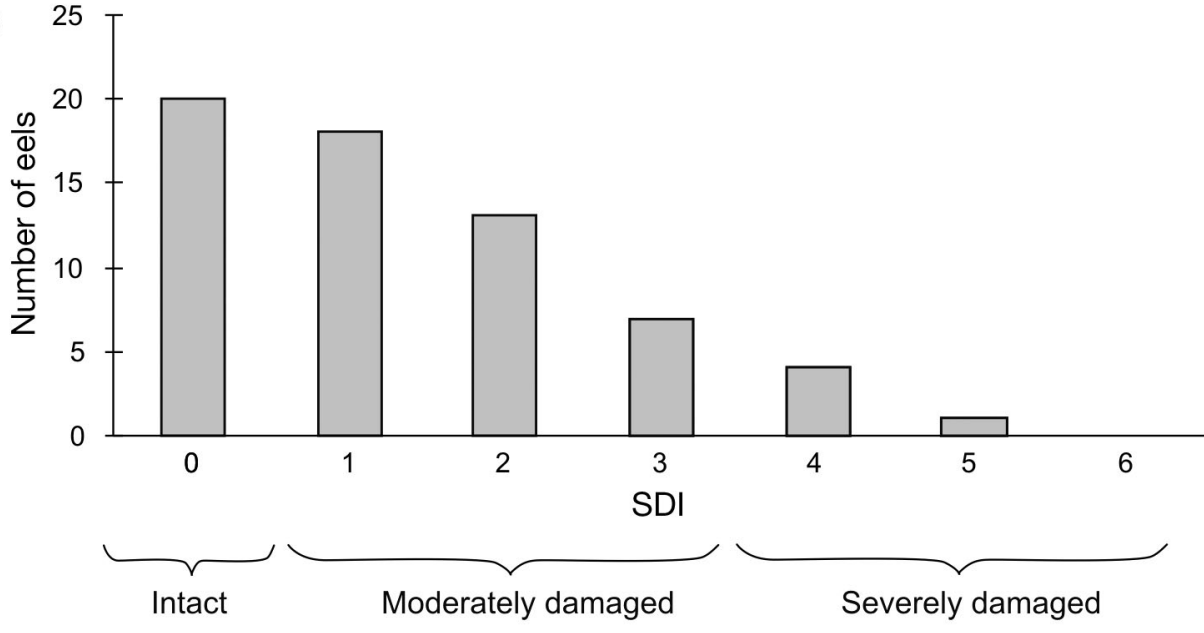

Fig. 4. Anguilla anguilla infected by Anguillicoloides crassus. Absolute frequency distribution (a) of the swimbladder degenerative index (SDI) and (b) of the 3 criteria used to assess it in eels from the Tagus estuary

ments, or other unclear factors. Therefore, it seems to be generally accepted that other biological and ecological aspects rather than host sex have a greater influence in Anguillicolloides crassus parasitism.

The nematode ability to infect eels irrespective of host size (Van Banning \& Haenen 1990) might explain why no significant differences in prevalence were found between size classes. In contrast, although some authors (e.g. Würtz et al. 1998) found no relationships between size and intensity of infection, most studies identified the same trend as observed in the Tagus estuary (e.g. Thomas \& Ollevier 1992, Audenaert et al. 2003, Schabuss et al. 2005). The increase in intensity of Anguillicolloides crassus infection with eel growth can be explained by the fact that larger eels have a longer exposure time to the parasite, a larger swimbladder and consequently a higher harbouring capacity, and distinct dietary habits comparative to smaller individuals, which might favour the consumption of more infected prey (Lefebvre et al. 2002b).

\section{Spatial variation}

Variation in prevalence of Anguillicolloides crassus based on host spatial distribution was only observed when a smaller geographic scale was considered and seems to be mostly influenced by the salinity gradient along the Tagus estuary. While some authors have reported the same trend as the present study (e.g. Sauvaget et al. 2003, Loukili \& Belghyti 2007), others have indicated that it might occur but failed to detect it (Lefebvre et al. 2002b, Norton et al. 2005, Morrissey \& McCarthy 2007). Although water salinity decreases egg hatching and larvae survival, nematode infectivity remains viable in saline conditions (Kennedy \& Fitch 1990, Kirk et al. 2000a). In fact, experimental studies indicated that the great majority of parasites osmoconform with their hosts in seawater, possibly because their bloodsucking activity provides them the necessary nutrients for osmotic regulation (Kirk et al. 2002). A recent study confirmed that, even in the wild, this parasite can reach prevalence in excess of $70 \%$ in waters where salinity ranged from 0.7 to 46.8 (Loukili \& Belghyti 2007). Therefore, even if this environmental variable can influence prevalence and partially explain the observed trend in the Tagus estuary, it is not totally clear why no parasitized eels were found in the most saline site.

Among the available literature, only Morrissey \& McCarthy (2007) captured eels harbouring no parasites in waters with salinity values similar to those observed in B. They pointed out that nematode absence might be related to the lack of intermediate and paratenic hosts, which is known to be a limiting factor in Anguillicol- 

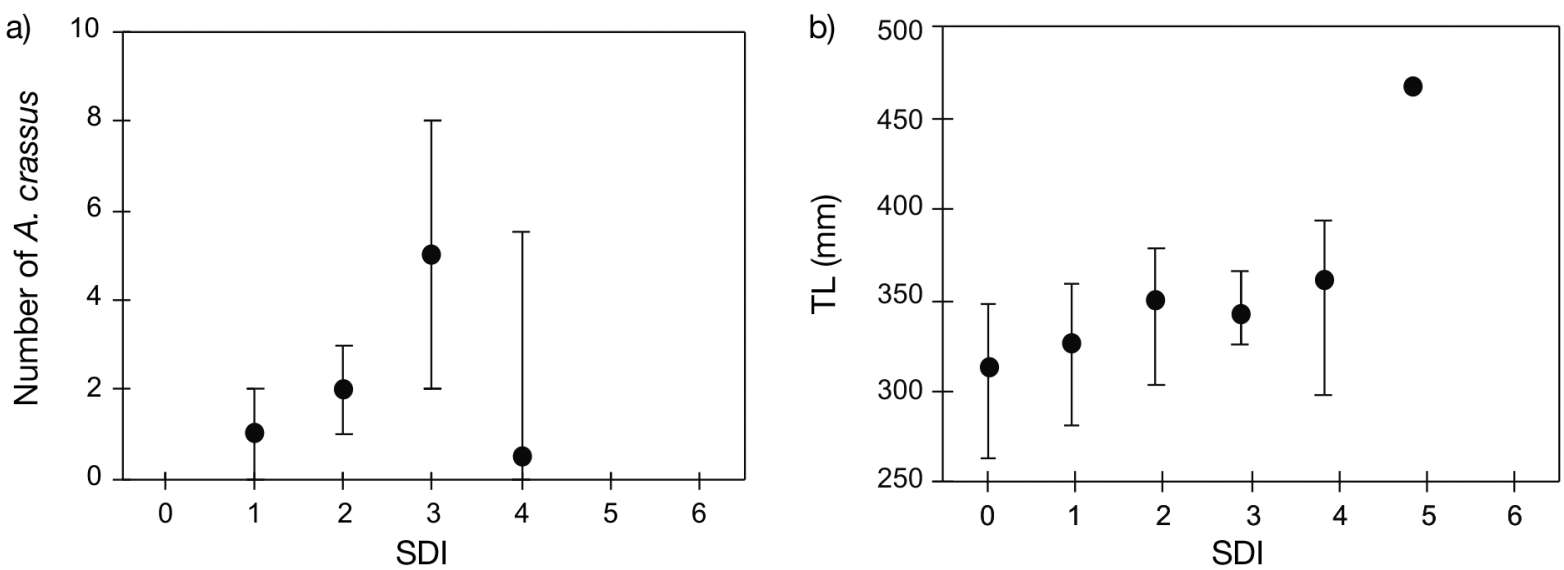

Fig. 5. Anguilla anguilla infected by Anguillicoloides crassus. (a) Parasite abundance and (b) host size (TL: total length) variation according to the swimbladder degenerative index (SDI) in eels from the Tagus estuary. Median values and interquartile ranges are represented

loides crassus spread (Kirk et al. 2000b). The same explanation can account for the results obtained in the present study, as eels from distinct areas in the Tagus estuary show a different dietary composition (Costa et al. 1992). Additionally, the reduced density of $A$. anguilla in the lower estuary (Costa et al. 2008) can also contribute by restricting parasite colonisation in this area. Similar to observations by Morrissey \& McCarthy (2007), the lack of infection in eels from B suggests that this nematode presence in upstream waters did not originate from eels migrating from a marine environment into freshwater.

Variation in intensity of infection based on host spatial distribution was only observed when a large geographic scale was considered and seems to be mostly related to the relatively high temperature verified in southern regions as well as in coastal lagoons, which promotes not only larval development and infectivity but also adult nematode growth, reproduction, and survival (Knopf et al. 1998).

\section{Swimbladder mechanical damage}

It is known that the presence of Anguillicolloides crassus can lead to a chronic inflammatory reaction in the swimbladder along with a fibrosis mechanism characterized by a thickening of its wall (e.g. Van Banning \& Haenen 1990, Haenen et al. 1996, Würtz \& Taraschewski 2000). However, thickening of the swimbladder wall was seldom observed in eels from the Tagus estuary, which can account for the lower mean SDI score obtained in comparison to those of other authors (Lefebvre \& Crivelli 2004). This result also suggests that eels have not suffered from repeated infection events during their lives (Van Banning \& Haenen
1990, Würtz \& Taraschewski 2000), as re-infected eels usually have more severely thickened swimbladders as well as haemorrhages and congestion of blood vessels than primary infected ones (Haenen et al. 1996). Nevertheless, because other symptoms were evident, it seems that some physiological changes had already occurred before gross histological damages could be detected. Those alterations might impair the mechanism of gas secretion and, consequently, reduce the amount of oxygen in the swimbladder lumen (Würtz et al. 1996).

In general, as a result of the nematode activity, increasing mechanical injuries can be explained by increasing parasite abundance. However, severely damaged swimbladders harboured fewer worms probably due to the fibrosis mechanism and consequent reduction in the swimbladder lumen volume (Würtz et al. 1998, Lefebvre et al. 2002a, Audenaert et al. 2003). Another important variable explaining swimbladder mechanical damages was size, suggesting not only that larger eels can harbour more nematodes, but also that pathological effects might accumulate during their lives (Lefebvre et al. 2002a, Lefebvre \& Crivelli 2004).

Table 2. Anguilla anguilla infected by Anguillicoloides crassus. Effects of different measures of parasite pressure on the health condition of eels from the Tagus estuary. Ab: parasite abundance index; SDI: swimbladder degenerative index

\begin{tabular}{|lccccc|}
\hline Variable & Covariate & Effect & df & $F$ & $\mathrm{p}$ \\
\hline Eviscerated & Total length & $\mathrm{Ab}$ & 2 & 0.354 & 0.878 \\
weight & & $\mathrm{SDI}$ & 5 & 1.132 & 0.354 \\
Liver & Eviscerated & $\mathrm{Ab}$ & 2 & 1.022 & 0.366 \\
weight & weight & $\mathrm{SDI}$ & 5 & 0.459 & 0.805 \\
Spleen & Eviscerated & $\mathrm{Ab}$ & 2 & 5.904 & $<0.01$ \\
weight & weight & $\mathrm{SDI}$ & 5 & 0.491 & 0.781 \\
\hline
\end{tabular}




\section{General health condition of eels}

The negative effects of Anguillicolloides crassus on its final host has generated enormous controversy among the scientific community (Kirk 2003). In the Tagus estuary, none of the measures tested had an effect on the eviscerated and liver weights of eels, which is in agreement with other studies (e.g. Möller et al. 1991, Thomas \& Ollevier 1992, Würtz et al. 1998, Lefebvre et al. 2004). Anguilla anguilla's major energetic reserve consists of lipids, which are predominantly stored as triglycerides in muscle tissues (Boëtius \& Boëtius 1985). However, as mentioned by Möller et al. (1991), the condition of wild eels shows a much greater variation compared to most other fish species and, as a result, smooth or moderate differences between parasitized and non-parasitized individuals are difficult to detect. That fact might also explain why no variation was observed in liver weight, despite being generally considered as an indicator of fish condition (Lambert \& Dutil 1997).

Lefebvre et al. (2004) stated that due to nematode activities, eels' adaptive processes involving spleen haematological and immunological functions might be impaired. Specifically, they argued that the observed spleen enlargement may result from hyper-synthesis of blood cells necessary to compensate for losses caused by the bloodsucking activity of the nematode as well as from hyper-synthesis of immune cells in response to tissue damage. In the present study, spleen weight increased with the number of lumen worms, indicating that this organ might be involved in the defence against the infection, probably counterbalancing potential blood costs. This result is also consistent with the fact that the analysed eels did not show severely damaged tissues. Several studies have reported that, in general, wild-caught infected eels do not show any evident variation in the majority of haematological parameters when compared to uninfected ones (Höglund et al. 1992, Kelly et al. 2000, Palíková \& Navrátil 2001). However, it is possible that, in the wild, parasite load may be an additional stressor if combined with environmental constraints (Kelly et al. 2000, Sures et al. 2001, Kirk 2003). For example, infected eels show a significant increased stress response when exposed to hypoxic conditions (Lefebvre et al. 2007).

\section{CONCLUSIONS}

The present results suggest that the swimbladder parasite in eels from the Tagus estuary is negatively affected by high salinity values. However, additional information is required to explain why eels from the lowest part of the estuary did not show any signs of infection. To achieve that aim, it would be important to identify the intermediate and paratenic hosts of this nematode, as well as to assess their parasitism load. This information would contribute towards a better knowledge of the circumstances that might have favoured the nematode spread in this ecosystem, help identify measures to counteract their effect, or enhance the effectiveness of specific actions that could be taken to preserve areas where eels remain uninfected. Anguillicolloides crassus epidemiology is of particular concern because the accumulation of pathological injuries in the swimbladder during eels' growth may cause an increasing vulnerability to adverse environmental conditions, which may ultimately prevent them from completing their life-cycle. A full understanding of the mechanisms involved in this parasite infection provides a major challenge for the future. Further research is needed not only to assess the general health of parasitized eels but also to focus on their physiological status and immunogenic response as well as on its importance in host-parasite coevolution.

Acknowledgements. This study was partially supported by Oceanário de Lisboa SA and by a postdoctoral grant (SFRH/BPD/38032/2007) from Fundação para a Ciência e a Tecnologia (FCT).

\section{LITERATURE CITED}

Audenaert V, Huyse T, Goemans G, Belpaire C, Volckaert FAM (2003) Spatio-temporal dynamics of the parasitic nematode Anguillicola crassus in Flanders, Belgium. Dis Aquat Org 56:223-233

Boëtius I, Boëtius J (1985) Lipid and protein content in Anguilla anguilla during growth and starvation. Dana 4:1-17

Bush AO, Lafferty KD, Lotz JM, Shostak AW (1997) Parasitology meets ecology on its own terms: Margolis et al. revisited. J Parasitol 83:575-583

Costa MJ (1999) O estuário do Tejo. Cotovia, Lisboa

- Costa JL, Assis CA, Almeida PR, Moreira FM, Costa MJ (1992) On the food of the European eel, Anguilla anguilla (L.), in the upper zone of the Tagus Estuary, Portugal. J Fish Biol 41:841-850

Costa JL, Domingos I, Assis CA, Almeida PR, Moreira FM, Feunteun E, Costa MJ (2008) Comparative ecology of the European eel, Anguilla anguilla (L., 1758), in a large Iberian River. Environ Biol Fishes 81:421-434

> De Charleroy D, Thomas K, Belpaire C, Ollevier F (1990) The life cycle of Anguillicola crassus. Dis Aquat Org 8:77-84

Domingos I (2003) A enguia-europeia, Anguilla anguilla (L., 1758), na bacia hidrográfica do Rio Mondego. PhD dissertation, Universidade de Lisboa

> Feunteun E (2002) Management and restoration of European eel population (Anguilla anguilla): an impossible bargain. Ecol Eng 18:575-591

Haenen OLM, Van Banning P (1990) Detection of larvae of Anguillicola crassus (an eel swimbladder nematode) in freshwater fish species. Aquaculture 87:103-109

> Haenen OLM, Grisez L, De Charleroy D, Belpaire C, Ollevier F (1989) Experimentally induced infections of European 
eel Anguilla anguilla with Anguillicola crassus (Nematoda, Dracunculoidea) and subsequent migration of larvae. Dis Aquat Org 7:97-101

> Haenen OLM, Van Wijngaarden TAM, Van der Heijden MHT, Höglund J and others (1996) Effects of experimental infections with different doses of Anguillicola crassus (Nematoda, Dracunculoidea) on European eel (Anguilla anguilla). Aquaculture 141:41-57

Höglund J, Andersson J, Härdig J (1992) Haematological responses in the European eel, Anguilla anguilla L., to sublethal infestation by Anguillicola crassus in a thermal effluent of the Swedish Baltic. J Fish Biol 15:507-514

Jakob EM, Marshall SD, Uetz GM (1996) Estimating fitness: a comparison of body condition indices. Oikos 77:61-67

Kelly CE, Kennedy CR, Brown JA (2000) Physiological status of wild European eels (Anguilla anguilla) infected with the parasitic nematode, Anguillicola crassus. Parasitology 120:195-202

Kennedy CR, Fitch DJ (1990) Colonization, larval survival and epidemiology of the nematode Anguillicola crassus, parasitic in the eel, Anguilla anguilla, in Britain. J Fish Biol 36: $117-131$

Kirk RS (2003) The impact of Anguillicola crassus on European eels. Fish Manag Ecol 10:385-394

Kirk RS, Kennedy CR, Lewis JW (2000a) Effect of salinity on hatching, survival and infectivity of Anguillicola crassus (Nematoda: Dracunculoidea) larvae. Dis Aquat Org 40: 211-218

Kirk RS, Lewis JW, Kennedy CR (2000b) Survival and transmission of Anguillicola crassus Kuwahara, Niimi \& Itagaki, 1974 (Nematoda) in seawater eels. Parasitology 120: 289-295

Kirk RS, Morritt D, Lewis JW, Kennedy CR (2002) The osmotic relationship of the swimbladder nematode Anguillicola crassus with seawater eels. Parasitology 124:339-347

Knopf K, Würtz J, Sures B, Taraschewski H (1998) Impact of low water temperature on the development of Anguillicola crassus in the final host Anguilla anguilla. Dis Aquat Org 33:143-149

Køie M (1991) Swimbladder nematodes (Anguillicola spp.) and gill monogeneans (Pseudodactylogyrus spp.) parasitic on the European eel (Anguilla anguilla). J Cons Int Explor Mer 47:391-398

- Lambert Y, Dutil JD (1997) Can simple condition indices be used to monitor and quantify seasonal changes in the energy reserves of Atlantic cod (Gadus morhua)? Can J Fish Aquat Sci 54:104-112

Lefebvre F, Crivelli AJ (2004) Anguillicolosis: dynamics of infection over two decades. Dis Aquat Org 62:227-232

Lefebvre F, Contournet P, Crivelli AJ (2002a) The health state of the eel swimbladder as a measure of parasite pressure by Anguillicola crassus. Parasitology 124:457-463

- Lefebvre F, Contournet P, Priour F, Soulas O, Crivelli AJ (2002b) Spatial and temporal variation in Anguillicola crassus counts: results of a 4 year survey of eels in Mediterranean lagoons. Dis Aquat Org 50:181-188

> Lefebvre F, Mounaix B, Poizat G, Crivelli AJ (2004) Impacts of the swimbladder nematode Anguillicola crassus on Anguilla anguilla: variations in liver and spleen masses. J Fish Biol 64:435-447

> Lefebvre F, Contournet P, Crivelli AJ (2007) Interaction between the severity of the infection by the nematode Anguillicola crassus and the tolerance to hypoxia in the European eel Anguilla anguilla. Acta Parasitol 52:171-175

Loukili A, Belghyti D (2007) The dynamics of the nematode Anguillicola crassus, Kuvahara 1974 in eel Anguilla anguilla (L. 1758) in the Sebou estuary (Morocco). Para- sitol Res 100:683-686

Möller H, Holst S, Lüchtenberg H, Petersen F (1991) Infection of eel Anguilla anguilla from the River Elbe estuary with two nematodes, Anguillicola crassus and Pseudoterranova decipiens. Dis Aquat Org 11:193-199

Moravec F (2006) Dracunculoid and anguillicoloid nematodes parasitic in vertebrates. Academia, Prague

Morrissey M, McCarthy TK (2007) The occurrence of Anguillicola crassus (Kuwahara, Niimi, and Hagaki, 1974), an introduced nematode, in an unexploited western Irish eel population. Biol Environ Proc R Ir Acad B 107:13-18

> Norton J, Rollinson D, Lewis JW (2005) Epidemiology of Anguillicola crassus in the European eel (Anguilla anguilla) from two rivers in southern England. Parasitology 130:679-686

Palíková M, Navrátil S (2001) Occurrence of Anguillicola crassus in the water reservoir Korycany (Czech Republic) and its influence on the health condition and haematological indices of eels. Acta Vet 70:443-449

Palstra AP, Heppener DFM, Van Ginneken VJT, Székely C, Van den Thillart GEEJM (2007) Swimming performance of silver eels is severely impaired by the swim-bladder parasite Anguillicola crassus. J Exp Mar Biol Ecol 352: $244-256$

Rózsa L, Reiczigel J, Majoros G (2000) Quantifying parasites in sample of hosts. J Parasitol 86:228-232

Sauvaget B, Fatin D, Briand C (2003) Contamination par Anguillicola crassus de cinq populations d'anguilles (Anguilla anguilla) du littoral de Bretagne Sud (France). Bull Fr Peche Piscicult 368:21-26

Schabuss M, Kennedy CR, Konecny R, Grillitsch B, Reckendorfer W, Schiemer F, Herzig A (2005) Dynamics and predicted decline of Anguillicola crassus infection in European eels, Anguilla anguilla, in Neusiedler See, Austria. J Helminthol 79:159-167

Siegel S, Castellan NJ Jr (1988) Nonparametric statistics for the behavioural sciences, 2nd edn. McGraw-Hill, New York

Sokal RR, Rohlf FJ (1995) Biometry: the principles and practice of statistics in biological research, 3rd edn. W.H. Freeman, New York

Sures B, Knopf K, Kloas W (2001) Induction of stress by the swimbladder nematode Anguillicola crassus in European eels, Anguilla anguilla, after repeated experimental infection. Parasitology 123:179-184

Tesch FW (1977) The eel: biology and management of anguillid eels. Chapman \& Hall, London

Thomas K, Ollevier F (1992) Population biology of Anguillicola crassus in the final host Anguilla anguilla. Dis Aquat Org 14:163-170

Van Banning P, Haenen OLM (1990) Effects of the swimbladder nematode Anguillicola crassus in wild and farmed eel, Anguilla anguilla. In: Perkins FO, Cheng TC (eds) Pathology in marine science. Academic Press, New York, p $317-330$

> Würtz J, Taraschewski H (2000) Histopathological changes in the swimbladder wall of the European eel Anguilla anguilla due to infections with Anguillicola crassus. Dis Aquat Org 39:121-134

Würtz J, Taraschewski H, Pelster B (1996) Changes in gas composition in the swimbladder of the European eel (Anguilla anguilla) infected with Anguillicola crassus (Nematoda). Parasitology 112:233-238

> Würtz J, Knopf K, Taraschewski H (1998) Distribution and prevalence of Anguillicola crassus (Nematoda) in eels Anguilla anguilla of the rivers Rhine and Naab, Germany. Dis Aquat Org 32:137-143 